\title{
Niveles de depresión en adultos mayores de Lima Metropolitana, marzo- junio 2012
}

\author{
Marcelina Rosas, Luisa Uribe, Milena López, Gladys Carlos, Ana María Llanos
}

Instituto de Ética en Salud, Facultad Medicina, UNMSM

\begin{abstract}
Objetivos: Determinar niveles de depresión en adultos mayores de Lima Metropolitana, marzo a junio 2012.
Diseño: Descriptivo, transversal

Institución: Instituto de Ética en Salud, Facultad Medicina, UNMSM.

Participantes: Adultos mayores.

Intervenciones: A 303 adultos mayores se efectuó análisis de datos, con aplicación de cuestionario estructurado.

Principales medidas de resultados: Características y porcentajes más relevantes en relación a depresión.

Resultados: Población predominantemente femenina $74,6 \%$, y en grupo etario de 66 a 70 años; $73,2 \%$ presentó depresión. La depresión fue menor en $42,2 \%$, siendo las mujeres de 60 a 65 años las de mayor porcentaje $(9,6 \%$ ) y los casados de ambos sexos, a predominio de mujeres entre 60 y 70 años $(28,9 \%$ ) y los varones con menores porcentajes. La depresión mayor estuvo en 26,7\%, siendo los de 66 a 70 años los más representativos, mujeres $6,9 \%$ y varones $3,6 \%$. Las casadas entre 65 y 70 años presentaron niveles altos, con 30,9\%.

Conclusiones: En la población estudiada, el 73,4\% presentó depresión, en relación de 3 a 1 con la población sin depresión. La población presentó mayormente depresión menor, con 42\%; sin embargo, es muy significativo observar que $31 \%$ presentó depresión mayor, siendo las mujeres casadas las que presentaron mayores índices (31\%).

Palabras clave: Adulto mayor, depresión.
\end{abstract}

\section{Confiabilidad y validez de un cuestionario sobre percepción del hostigamiento sexual en estudiantes universitarios}

Violeta Nolberto, Martha Martina, Olga Bardales, Deysi Gálvez, Hernán Vásquez, Socorro Torres

Universidad Nacional Mayor de San Marcos, Lima, Perú

Introducción: El hostigamiento sexual en el ámbito laboral es de conocimiento y objeto de denuncia por sus víctimas; sin embargo, son escasas las evidencias científicas en el ámbito universitario.

Objetivos: Desarrollar un cuestionario que proporcione datos confiables y válidos sobre la percepción de hostigamiento sexual en estudiantes universitarios.

Diseño: Evaluación psicométrica de pruebas empíricas.

Institución: Universidad Nacional Mayor de San Marcos, Lima, Perú.

Participantes: Estudiantes matriculados.

Intervenciones: Cuestionario de 31 items a 189 estudiantes matriculados.

Principales medidas de resultados: La confiabilidad global del instrumento fue de 0,924. El análisis factorial exploratorio con rotación varimax dio un valor de convergencia general que explica el $64,75 \%$ de la varianza total. La estructura factorial permitió identificar cinco factores: el primero, percepción de formas de acoso a través de mensajes y conductas explícitas; el segundo, percepción sobre formas de acoso a través de la comunicación verbal y no verbal; el tercero, percepción sobre formas directas de acoso de parte de los docentes; el cuarto, situaciones de acoso en donde la conducta sexual está involucrada; y, el quinto, percepciones de situaciones sutiles de acoso de parte de los profesores.

Conclusión: El cuestionario tuvo alta consistencia interna y validez apropiada para medir la percepción del hostigamiento sexual en estudiantes universitarios.

Palabras clave: Hostigamiento sexual, confiabilidad, validez factorial, estudiante universitario. 